René König · Schriften 
René König · Schriften · Ausgabe letzter Hand

Herausgegeben von

Heine von Alemann

Hans-Joachim Hummell

Oliver König

Hans Peter Thurn

Band 12 


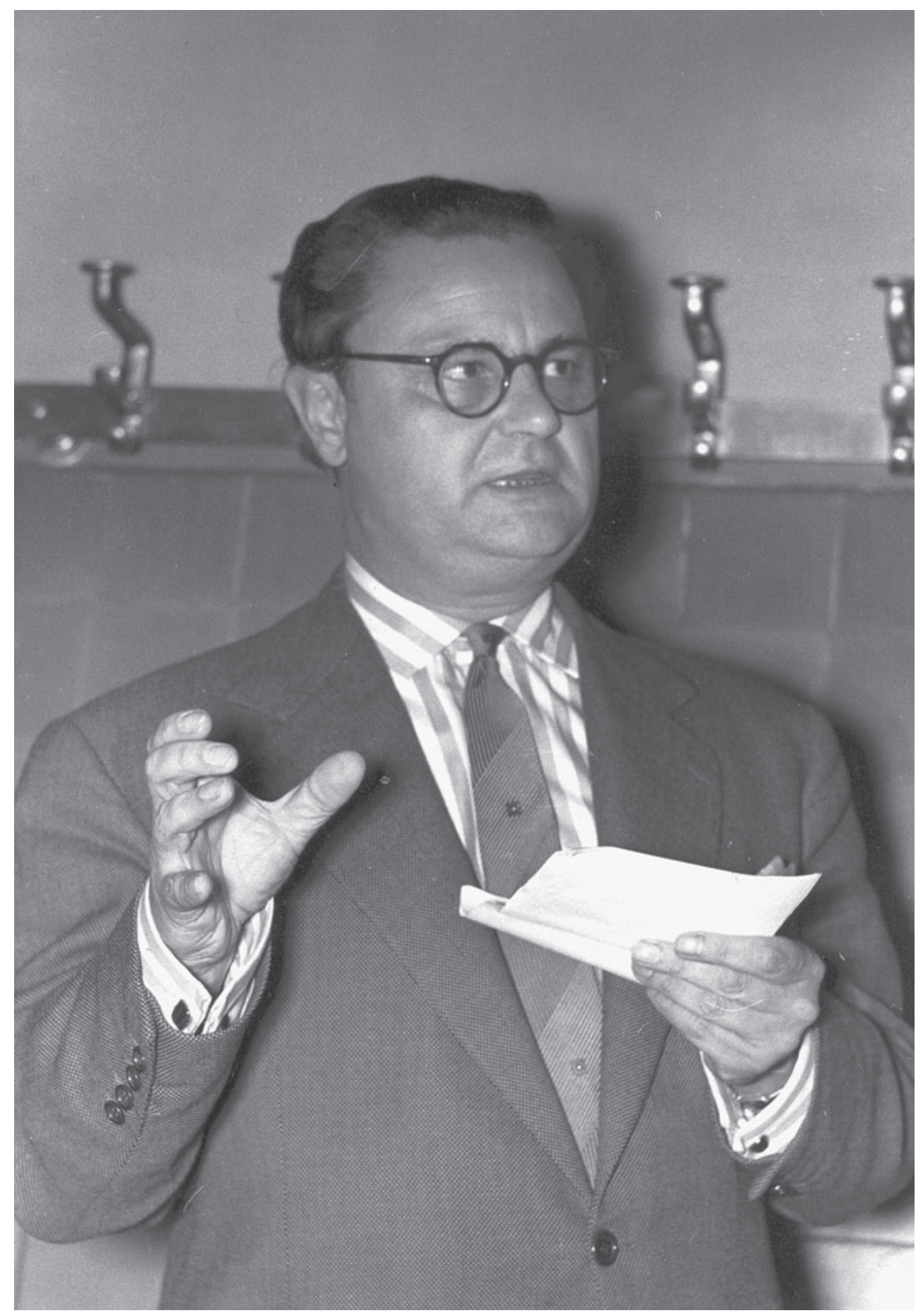


René König

\section{Strukturanalyse der Gegenwart}

Herausgegeben und mit einem Nachwort versehen von Michael Klein

望 Springer VS 
Frontispiz: René König am 14. Juli 1954 bei den Mittwochsgesprächen im „Alten Wartesaal" des Kölner Hauptbahnhofes.

Foto von Peter Fischer (Historisches Archiv der Stadt Köln)

ISBN 978-3-531-14783-3

Die Deutsche Nationalbibliothek verzeichnet diese Publikation in der Deutschen Nationalbibliografie; detaillierte bibliografische Daten sind im Internet über http:/ / dnb.d-nb.de abrufbar.

\section{Springer VS}

(C) Springer Fachmedien Wiesbaden 2016, Nachdruck der Hardcover-Ausgabe von 2006 Das Werk einschließlich aller seiner Teile ist urheberrechtlich geschützt. Jede Verwertung, die nicht ausdrücklich vom Urheberrechtsgesetz zugelassen ist, bedarf der vorherigen Zustimmung des Verlags. Das gilt insbesondere für Vervielfältigungen, Bearbeitungen, Übersetzungen, Mikroverfilmungen und die Einspeicherung und Verarbeitung in elektronischen Systemen.

Die Wiedergabe von Gebrauchsnamen, Handelsnamen, Warenbezeichnungen usw. in diesem Werk berechtigt auch ohne besondere Kennzeichnung nicht zu der Annahme, dass solche Namen im Sinne der Warenzeichen- und Markenschutz-Gesetzgebung als frei zu betrachten wären und daher von jedermann benutzt werden dürften.

Der Verlag, die Autoren und die Herausgeber gehen davon aus, dass die Angaben und Informationen in diesem Werk zum Zeitpunkt der Veröffentlichung vollständig und korrekt sind. Weder der Verlag noch die Autoren oder die Herausgeber übernehmen, ausdrücklich oder implizit, Gewähr für den Inhalt des Werkes, etwaige Fehler oder Äußerungen.

Gedruckt auf säurefreiem und chlorfrei gebleichtem Papier

Springer VS ist Teil von Springer Nature

Die eingetragene Gesellschaft ist Springer Fachmedien Wiesbaden GmbH 


\section{Inhalt}

Zur Einführung …………………………………………………...

Soziologische Orientierungen ................................................................ 7

Der Mensch in der Sicht des Soziologen ....………………………....... 10

Allgemeine Strukturanalyse und Entwicklungssoziologie ........ 25

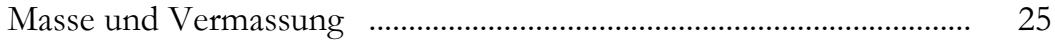

Gestaltungsprobleme der Massengesellschaft ...……………………... 37

Die Gesellschaft von heute zwischen gestern und morgen ............... 52

Zeitbewußtsein und sozialer Wandel ................................................. 62

Strukturwandlungen unserer Gesellschaft und einige

Auswirkungen auf die Krankenversicherung ....................................... $\quad 71$

Die Gesellschaftsstruktur in der Bundesrepublik und ihr Wandel von 1945 bis heute ................................................................ 92

Betrachtungen zur Strukturanalyse der Gegenwart ........................... 106

Einleitung zu einer Soziologie der sogenannten

rückständigen Gebiete ....................................................................... 126

Konsum und Ernährung …………………………………………... 145

Das Problem der Nachahmung - Ihre Wirkung im Aufbau

des Konsums …………………………………………………... 145

Können Konsumgewohnheiten beeinflußt oder

verändert werden?

Konsumgewohnheiten und Konsumenten in der heutigen

Gesellschaft - Erkenntnisse der Soziologie .......................................... 176

Die soziale und kulturelle Bedeutung der Ernährung in der

industriellen Gesellschaft

Alter, Jugend und Geschlecht

Die strukturelle Bedeutung des Alters in den

fortgeschrittenen Industriegesellschaften

Jugendlichkeit als Ideal moderner Gesellschaften ............................. 203

Ist das Kunsterleben der Jugend konventionell? .................................. 210 
Die Stellung der Frau in der modernen Gesellschaft ........................ 214 Probleme der Berufswahl von Mädchen aus unvollständigen Familien ................................................................... 295

Gleichberechtigung von Mann und Frau soziologisch gesehen ....... 312

Person und Kultur ........................................................................... 325

Bemerkungen zur Sozialpsychologie ................................................. 325

I. Das Erlernen der Kultur ........................................................... 325

II. Das Nachhinken der Kultur .......................................................... 332

III. Die pluralistische Gesellschaft und ihre Subkulturen ................ 339

IV. Die objektiven Kulturmächte und ihre sozialen Auswirkungen .... 346

Probleme der Medizin-Soziologie ...................................................... 352

Psychoanalyse und sozialer Wandel f................................................. 361

Editorische Notiz ............................................................................. 373

Publikationsnachweise zu den einzelnen Beiträgen ............................ 373

Nachwort von Michael Klein ....................................................... 377

Personenregister f.............................................................. 413 